\title{
REGULACION DEL METABOLISMO: EFECTO DE LAS DIETAS SOBRE LA ACTIVIDAD DE LAS ENZIMAS
}

RaúlParedes Medina'

\section{RESUMEN}

Un grupo de ratas albinas fueron mantenidas en ayunas y otro grupo se sobrealimentaron para estudiar el efecto de las dietas sobre la actividad de las enzimas. Glucosa -6-fosfato deshidrogenasa, Piruvato Quinasa, Malico Deshidrogenasa yla Fructosa 1,6Difosfatasa, las quefueronobtenidas del higado delos animales, mediante el homogenizado y una centrifugación, asi el citosol que fue incubado y leido en un espectrofotometro, de cuyas absorbancias se calcularon sus actividades que muestran un incremento para las ratas sobrealimentadas, mientras que en las mantenidas en ayunas, se incrementala gluconeogénesis y se presenta un decremento en la actividad de ciertas enzimas glicolíticas y lipogénicas.

\section{INTRODUCCION}

Las enzimas: Glucosa-6-Fosfato Deshidrogenasa (G6FD), Piruvato Quinasa(PK), Málico Deshidrogenasa yla Fructosa 1;6Difosfatasa(FDPasa), intervienen en el metabolismo de los glúcidos.

La enzima Piruvato Quinasa cataliza la conversión del fosfoenol piruvato (PEP) en piruvato:

$\mathrm{PEP}+\mathrm{ADP} \stackrel{\mathrm{PK}}{\longrightarrow}$ Piruvato+ATP $+\triangle \mathrm{G}^{\circ}=-7,5 \mathrm{Kcal} / \mathrm{mol}$

LaFructosa-Di-fosfatasa (FDPasa), llamadatambién como "Hexosadi-fosfatasa", cataliza la conversión de la fructosa-1;6-difostato en Fructosa-6-fosfato:

$\mathrm{F}-1 ; 6-\mathrm{DP}+\mathrm{H}_{2} \mathrm{O} \stackrel{\mathrm{FDPasa}}{\rightleftharpoons} \mathrm{F} 6 \mathrm{P}+\mathrm{Pi}+\Delta \mathrm{G}^{\circ}=-4,0 \mathrm{Kcal} / \mathrm{mol}$

La Glucosa-6-fosfato deshidrogenasa (G6FD) cataliza la conversión de la Glucosa-6-fosfato (G-6-P) en 6-fosfogluconolactona, en la primera reacción de la ruta delfosfogluconato:

G-6-P+NADP+ $\stackrel{\text { G6FD }}{\longrightarrow} 6$-fosfoglucono- $\delta$-lactona

$+\mathrm{NADPH}+\mathrm{H}^{+}+\Delta \mathrm{G}^{\circ}=-0,1 \mathrm{Kcal} / \mathrm{mol}$

La enzima Malato Deshidrogenasa es dependiente del NADP, se encuentra en el citosol y convierte matato en piruvato $(\mathrm{Pir})$ :

1. Magíster en bioquímica
$\mathrm{L}-$ malato+NADP $\stackrel{\begin{array}{c}\text { L-malato } \\ \text { desidrogenasa }\end{array}}{=} \mathrm{Pir}+\mathrm{CO}_{2}+\mathrm{NADPH}+\mathrm{H}^{+}$

$+\Delta \mathrm{G}^{\circ}=+7,1 \mathrm{Kcal} / \mathrm{mol}$

\section{MATERIAL Y METODOS}

Se trabajó con ratas albinas aproximadamente de 200 gramos, divididas en dos grupos: un grupo fue sometido a ayunas por 48 horas y el otro grupo sometido a ayunos por 48 horas yluego sobrealimentadas con una dieta alta en calorías y baja en proteínas y grasas durante 7 días.

Se utilizaron: bisturí, tijeras, tubos de ensayo, pipetas, homogenizador, balanzaanalítica, centrifugadora, termostato, espectrofotómetro Gilford 240, pH-metro.

Se usaron: $\mathrm{HC} 1600 \mathrm{mM}$, dithioeritritol 0,48 mM, $\mathrm{MgCL}_{2} 20 \mathrm{mM}$, EDTA $20 \mathrm{mM}$, TEA $5 \mathrm{mM}, \mathrm{KOH}$, solución de Biuret, Buffer Tris HCL 0,05 M pH 8,8; NADP 7,5 mg/ $\mathrm{ml}, \mathrm{MgCL}_{2}$ 0,1 m, G-6-P 11,3/2ml, NaCL, Buffer Trismaleato $0,1 \mathrm{M} \mathrm{pH} 7,2$; ADP 4,6 x $10 \mathrm{M}, \mathrm{MgSO}_{4} 1,584 \times$ $10 \mathrm{M}, \mathrm{KCL} 1,35 \mathrm{M}, \mathrm{DPNH} 3 \times 10 \mathrm{M}$, LDH libre de PK 990 $\mathrm{U} / \mathrm{ml}$, PEP 1,56 X 10-2M; Buffer glicilglicerina $0,25 \mathrm{M} \mathrm{pH}$ 7,$4 ; \mathrm{MgSO}_{4} 0,05 \mathrm{M}$, TPN 0,000675 M, Buffer Tris $0,5 \mathrm{M}$ $\mathrm{pH} 7,5$; NADP $0,2 \mathrm{mM}(15,6 \mathrm{mg} / \mathrm{ml})$, EDTA $10 \mathrm{uM} / \mathrm{ml}$, $\mathrm{MgCL}_{2} 500 \mathrm{uM} / \mathrm{ml}$, $\left(\mathrm{NH}_{4}\right)_{2} \mathrm{SO}_{4} 1 \mathrm{M}$, fosfoexosa-isomerasa, FDP $4,20 \mathrm{mg} / \mathrm{ml}$, agua bidestilada.

Los hígados de rata se pesan, se trituran y se homogenizan en una solución de $100 \mathrm{ml}$, preparada de la siguiente manera: 
$\mathrm{HCL}$

Dithioeritritol 0,48 mM

$=25 \mathrm{ml}$

$=25 \mathrm{ml}$

$\mathrm{MgCL}_{2} 20 \mathrm{mM}$

EDTA $20 \mathrm{mM}$

$=25 \mathrm{ml}$

$=25 \mathrm{ml}$

Se añade TEA $=92,80 \mathrm{mg} / 100 \mathrm{ml}$ del medio salino (TEA $=$ Trietanol amina hidroclorhídrico), luego se lleva apH $=7,8$ con $\mathrm{KOH}$, asípreparado el homogeneizado se centrifuga a 40000 RPM durante 60 minutos. Luego se elimina la grasa del sobrenadante con papel filtro para obtener el citosol (sobrenadante).

Las determinaciones enzimáticas y lecturas de absorbancia se realizaron tal como se indica:

a) Para la Glucosa-6-Fosfato Deshidrogenasa: para una cubeta de $3,00 \mathrm{ml}$, se emplearon dos tubos de ensayo, colocando en cada uno los reactivos:

$\begin{array}{ll}\text { Buffer Tris-HCL } 0,05 \mathrm{M} \mathrm{pH} 8,8 & =0,50 \mathrm{ml} \\ \text { NADP } 7,5 \mathrm{mg} / \mathrm{ml} & =0,10 \mathrm{ml} \\ \text { MgCL2 } 0,1 \mathrm{M} & =0,40 \mathrm{ml} \\ \text { Enzima (citosol) } & =0,10 \mathrm{ml} \\ \mathrm{H}_{2} \mathrm{O} \text { bidestilada } & =0,80 \mathrm{ml}\end{array}$

Se mezclan y se incuban a $30^{\circ}$ por cinco minutos, luego se añade G-6-P $(11,3 / 2 \mathrm{ml})$ más $0,10 \mathrm{ml}$ sal de sodio para iniciar la reacción. Se vierte en una cubeta de $3,00 \mathrm{ml}$ y se lee en el espectrofotómetro a $340 \mathrm{~nm}$ con filtro azul, obteniéndose así las absorbancias.

b) Para la Piruvato Quinasa: se prepara el medio de ensayo con los siguientes reactivos:

$\begin{array}{ll}\text { Buffer Tris-maleato } 0,1 \mathrm{M} \mathrm{pH} 7,2 & =5,00 \mathrm{ml} \\ \text { ADP } 4,6 \times 10 \mathrm{M} & =0,50 \mathrm{ml} . \\ \mathrm{MgSO}_{4} 1,584 \times 10 \mathrm{M} & =0,50 \mathrm{ml} . \\ \mathrm{KCL} 1,35 \mathrm{M} & =0,50 \mathrm{ml} .\end{array}$

Para una cubeta de $1,00 \mathrm{ml}$, se mezclan en un tubo de ensayo los siguientes reactivos:

Medio (lopreparado anteriormente) $=0,65 \mathrm{ml}$

DPNH $3 \times 10 \mathrm{M}$

$=0,05 \mathrm{ml}$

LDH libre de PK $990 \mathrm{U} / \mathrm{ml}$

$=0,01 \mathrm{ml}$

Enzima (citosol)

$=0,01 \mathrm{ml}$

$\mathrm{H}_{2} \mathrm{O}$ bidestilada

$=0,18 \mathrm{ml}$

( $\mathrm{LDH}=$ láctico deshidrogenasa, $\mathrm{PK}=$ piruvato quinasa)

Se incuba a $30^{\circ} \mathrm{C}$ porcinco minutos. La reacción empieza al añadir PEP $\left(1,56 \times 10^{-2} \mathrm{M}\right)=0,05 \mathrm{ml}$. Se vierte en una cubeta de $1,00 \mathrm{ml}$ y se lee el cambio de absorbancia, a $340 \mathrm{~nm}$ con filtro azul.

c) Para la Fructosa 1;6 Difosfatasa: para un volumen de $1,00 \mathrm{ml}$, el medio de ensayo se prepara de la siguiente manera:
Buffer Tris $0,5 \mathrm{M} \mathrm{pH} 7,5$

NADP O,2 mM (15,6 mg/ml)

$\operatorname{EDTA}(10 \mathrm{uM} / \mathrm{ml})$

$\mathrm{MgCL}_{2}(500 \mathrm{uM} / \mathrm{ml}$

$\left(\mathrm{NH}_{4}\right)_{2} \mathrm{SO}_{4} 1 \mathrm{M}$

Fosfoexosa-isomerasa

$\operatorname{FDP}(4,20 \mathrm{mg} / \mathrm{ml})$

$=1,00 \mathrm{ml}$

$=0,10 \mathrm{ml}$

$=0,10 \mathrm{ml}$

$=0,10 \mathrm{ml}$

$=0,40 \mathrm{ml}$

$=0,02 \mathrm{ml}$

$=0,10 \mathrm{ml}$

Toda la mezcla se ajusta a $\mathrm{pH} 7,5$ y se completa con agua bidestilada hasta un volumen de $10 \mathrm{ml}$.

En otro tubo de ensayo se ponen los reactivos:

Medio de ensayo (anteriorpreparado) $=0,95 \mathrm{ml}$

Glucosa-6-fosfato-deshidrogenasa $=0,005 \mathrm{ml}$

$\mathrm{H}_{2} \mathrm{O}$ bidestilada

$=$ variable

Se incuba $30^{\circ} \mathrm{C}$ porcinco minutos. La reacción se inicia añadiendo la enzima (citosol) de 5 a 10 lambdas $(0,005$ y $0,010 \mathrm{ml}$, respectivamente). Se vierte en una cubeta y se leen sus absorbancias a 340 $n m$ en un espectrofotómetro de filtro azul.

d) Para la Málico Deshidrogenasa (NADP dependiente): para una cubeta de $3,00 \mathrm{ml}$ se colocan en un tubo de ensayo los reactivos:

Buffer glicilglicerina $0,25 \mathrm{M} \mathrm{pH} 7,4=0,30 \mathrm{ml}$

$\mathrm{MgSO}_{4} 0,05 \mathrm{M} \quad=0,10 \mathrm{ml}$

TPN $0,000675 \mathrm{M} \quad=0,20 \mathrm{ml}$

Enzima (citosol) $\quad=0,20 \mathrm{ml}$

$\mathrm{H}_{2} \mathrm{O}$ bidestilada $\quad=2,19 \mathrm{ml}$

Se incuba a $30^{\circ} \mathrm{C}$ por cinco minutos. La reacción se inicia al añadir 0,05 $\mathrm{ml}$ de L-malato 0,030 M. Se vierte en una cubeta y junto con otra cubeta sin TPN que sirve de blanco, se leen sus cambios de absorbancia en un espectrofotómetro de filtro azul a $340 \mathrm{~nm}$.

En la determinación de la proteína, se empleó el método de Biuret. Para ello, se colocan en tres tubos de ensayo los siguientes componentes:

\begin{tabular}{|l|r|r|r|}
\hline \multirow{2}{*}{ COMPONENTES } & \multicolumn{3}{|c|}{ CANTIDAD (ml) } \\
\cline { 2 - 4 } & 1 & 2 & 3 \\
\hline Enzima (citosol) & 0,10 & 0,20 & $\cdots$ \\
$\mathrm{H}_{2} \mathrm{O}$ bidestilada & 0,90 & 0,80 & 1,00 \\
Biuret & 4,00 & 4,00 & 4,00 \\
\hline
\end{tabular}

Se dejaron en reposo por 30 minutos, luego se leyeron los cambios de absorbancia en un espectrofotómetro a $540 \mathrm{~nm}$. 
RESULTADOS

CUADRO No. 01: Cambios de absorbancia.

\begin{tabular}{|c|c|c|c|}
\hline $\begin{array}{l}\text { ENZIMA } \\
\text { (TIPO) }\end{array}$ & $\begin{array}{c}\text { CITOSOL } \\
(\mathrm{ml})\end{array}$ & $\begin{array}{c}\triangle \mathrm{A} / \mathrm{min} \\
\text { RATAS EN } \\
\text { AYUNAS }\end{array}$ & $\begin{array}{c}\triangle \mathrm{A} / \mathrm{min} \\
\text { RATAS } \\
\text { SOBREALIM. }\end{array}$ \\
\hline $\begin{array}{l}\text { Glucosa-6-Fosfato } \\
\text { Deshidrogenasa }\end{array}$ & $\begin{array}{l}0,10 \\
0,20\end{array}$ & $\begin{array}{l}0,05 \\
0,09\end{array}$ & $\begin{array}{l}0,05 \\
0,09\end{array}$ \\
\hline Piruvatro Quinasa & $\begin{array}{l}0,025 \\
0,050\end{array}$ & $\begin{array}{l}0,012 \\
0,022\end{array}$ & \\
\hline Málico Deshidrogenasa & $\begin{array}{l}0,10 \\
0,15\end{array}$ & 0,005 & 0,006 \\
\hline Fructosa $1 ; 6$ Diifosfatasa & $\begin{array}{l}0,005 \\
0,010\end{array}$ & 0,032 & $\begin{array}{l}0,014 \\
0,020\end{array}$ \\
\hline
\end{tabular}

\section{CALCULO}

La concentración de las proteínas se ha calculado mediante la relación:

$$
C=\frac{\triangle A \times F C}{V}
$$

C = concentración de la proteína $(\mathrm{mg} / \mathrm{ml})$

$\triangle \mathrm{A}=$ cambio de absorbancia

$\mathrm{FC}=20$ (factor de calibración)

$\mathrm{V}=$ volumen de enzima (citosol)

CUADRO No.02: Concentración de proteínas.

\begin{tabular}{|c|c|c|c|}
\hline \multicolumn{2}{|c|}{ RATAS EN AYUNAS (A) } & \multicolumn{2}{|c|}{$\begin{array}{l}\text { RATAS SOBREALIMENTADAS } \\
(\mathrm{B})\end{array}$} \\
\hline$\Delta \mathrm{A} / \mathrm{min}$ & $\begin{array}{c}\text { Concentr. } \\
\text { Prot. }(\mathrm{mg} / \mathrm{ml})\end{array}$ & $\Delta \mathrm{A} / \mathrm{min}$ & $\begin{array}{c}\text { Concentr. } \\
\text { Prot. }(\mathrm{mg} / \mathrm{ml})\end{array}$ \\
\hline 0,054 & 10,80 & 0,045 & 9,00 \\
\hline \multirow[t]{3}{*}{0,114} & 11,40 & 0,056 & 11,20 \\
\hline & & 0,100 & 10,00 \\
\hline & & 0,099 & 9,90 \\
\hline PROMEDIO & 11,10 & & 10,00 \\
\hline
\end{tabular}

La Actividad de las enzimas se han calculado mediante la siguiente relación:

$$
\text { Act. }=\frac{\Delta \mathrm{A} / \mathrm{min}}{\varepsilon \times \mathrm{V}}
$$

$\mathcal{E}=$ coeficiente de extinción molar $(2,07$ para cubeta de $3 \mathrm{ml} ; 6,22$ para cubeta de $1,00 \mathrm{ml}$ )

$\mathrm{V}=$ volumen (alícuotas de enzima)
CUADRO No. 03: Promedio de las actividades.

\begin{tabular}{|l|c|c|l|}
\hline \multirow{2}{*}{ E N ZIM A } & ACT. RATAS $(\mathrm{A})$ & ACT. RATAS $(\mathrm{B})$ & PROMEDIO \\
\cline { 2 - 4 } & $(\mathrm{U} / \mathrm{ml})$ & $(\mathrm{U} / \mathrm{ml})$ & $(\mathrm{U} / \mathrm{ml})$ \\
\hline G-6-P Deshidr. & 0,22945 & 0,22945 & 0,22945 \\
Pir-Quinasa & 0,07395 & 0,05790 & 0,06592 \\
Málico Deshidr. & 0,02410 & 0,01930 & 0,02170 \\
F-1;6-DiPasa & 0,51050 & 0,38585 & 0,45020 \\
\hline
\end{tabular}

La Actividad Específica de las enzimas en $\mu$ moles $/ \mathrm{min} / \mathrm{mg}$ de proteína y en $\mathrm{m} \mu$ moles $/ \mathrm{min} / \mathrm{mg}$ de prot. se calcularon mediante la relación:

Act. Esp. $=\frac{\Delta \mathrm{A} / \mathrm{min}}{\varepsilon \times V \text { mg prot. } \times \mathrm{ml}}$

CUADRO No. 04: Promedio de las actividades específicas.

\begin{tabular}{|l|c|c|c|}
\hline \multirow{2}{*}{ ENZIM A } & \multicolumn{3}{|c|}{$\mathrm{m} \mu$ moles / min / mg de proteína } \\
\cline { 2 - 4 } & RATAS (A) & RATAS (B) & PROMEDIO \\
\hline G-6-P Deshidr. & 21,00 & 22,945 & 21,97 \\
Pir-Quinasa & 6,66 & 5,79 & 6,22 \\
MálicoDeshidr. & 2,20 & 1,93 & 2,06 \\
F-1;6-DiPasa & 46,35 & 38,585 & 42,47 \\
\hline
\end{tabular}

También se han calculado las actividades en Unidades por mililitro $(\mathrm{U} / \mathrm{ml})$ yen Unidades porgramo de tejido (U/g tej.). Los resultados y la comparación se dan en el siguiente cuadro:

CUADRO No. 05: Comparación de actividades.

\begin{tabular}{|l|r|r|r|r|r|r|}
\hline \multirow{2}{*}{ E N ZIM A } & \multicolumn{3}{|c|}{$\begin{array}{r}\text { RATAS EN AYUNAS (48 } \\
\text { HORAS) }\end{array}$} & \multicolumn{3}{c|}{$\begin{array}{c}\text { RATAS } \\
\text { SOBREALIMENTADAS }\end{array}$} \\
\cline { 2 - 7 } & U/ml & U/g tej. & $\triangle \mathrm{A}$ & U/ml & U/g tej. & \multicolumn{1}{c|}{$\Delta \mathrm{B}$} \\
\hline G-6-P Deshidr. & 0,229 & 2,031 & 21,97 & 0,782 & 6,647 & 57,70 \\
Pir-Quinasa & 0,066 & 0,581 & 6,22 & 2,994 & 25,451 & 220,85 \\
Mál. Deshidr. & 0,022 & 0,191 & 2,06 & 0,058 & 0,496 & 4,30 \\
FDPasa & 0,450 & 3,968 & 42,47 & 0,165 & 1,400 & 12,10 \\
\hline
\end{tabular}

$\triangle A$ y $\triangle B$ se refieren a las actividades de las ratas en ayunas y de las sobrealimentadas, respectivamente, como promedio en $\mathrm{m} \mu$ moles / min / mg prot.

\section{DISCUSION}

Las actividades de las enzimas Glucosa-6- 
Fosfato Deshidrogenasa, Piruvato Quinasay de la Málico Deshidrogenasa han experimentado un incremento (cuadro No. 05) en el grupo de ratas sobrealimentadas, con una dieta alta en carbohidratos y baja en proteínas y grasas. Elmayor incremento ha experimentadolaPiruvato Quinasa que, prácticamente, se ha elevado hasta unas 36 veces en su Actividad Específica, mientras que la enzima Gluconeogénica Fructosa-1;6-Di-fosfatasa experimentó un decremento en su actividad hasta en unas 3,5 veces. Los incrementos y decrementos en la Actividad Específica de las enzimas demuestran que, durante el ayuno, se produce en los animales un incremento de la gluconeogénesis y un decremento en la actividad de ciertas enzimas glicolíticas y lipogénicas, tal es así que las enzimas involucradas en la síntesis de los ácidos grasos comola Glucosa-6-Fosfato Deshidrogenasa y la Malato Deshidrogenasa de los animales sobrealimentados aumentaron sus actividades en un poco más del doble; en cambio, la Piruvato Quinasa involucrada en la glicólisis fue la enzima que menos incremento experimentó. Porúltimo, la enzima Fructosa1;6-Difosfatasa, necesaria para la gluconeogénesis, cuadruplicó su actividad.

Ciertas condiciones gluconeogénicas como: el ayuno, la sobrealimentación, los ejercicios violentos y la administración de ciertas hormonas como la Triamcinolona, están asociados con el incremento de la gluconeogénesis y el decremento en la actividad

\section{BIBLIOGRAFIA}

Ashmore, J. and Weber, G. (1968): Carbohidrate Metabolic Disease. Editado por Dickens, Academic Press. vol. 1: 336.

Bohinski, R. C. (1978): Bioquímica. Ed. Fondo Educativo Interamericano S.A. USA. 368-373.

Gunn, J. M. and Taylor, C. B. (1973): Relationships between concentration of hepatic intermediary metabolites and induction of the key glycolytic enzymes in vivo. Biochem J. 136: 455 proteolítica de ciertas enzimas glicolíticas en el hígado de los animales. En el caso específico de la Fructosa$1 ; 6$-Difosfatasa, varios investigadores señalanque algunas condiciones gluconeogénicas como las mencionadas, están asociadas con la pérdida de una proteína en la periferie de los tejidos, así como el incremento de la actividad proteolítica en el hígado-por ayuno prolongado, siendo mayores los incrementos en las actividades gluconeogénicas de las enzimas hepáticas. Estos, probablemente, involucran la intervención gluconeogénica de ciertas hormonas desde el incremento similar en la actividad lisosomal. Nuestros resultados son coincidentes con los reportados por Pérez y col. (1964), pues ellos demuestran que el efecto de la dieta sobre la Glucoquinasa y las otras enzimas, con una dieta rica en carbohidratos, incrementa sus actividades y con el ayuno vieron un decremento, tal como sucedió en el presente trabajo. Esto estaría en relación a una mayor o menor liberación de insulina según la dieta. Ashmore y Weber (1968) consideran que las enzimas glicolíticas, como las estudiadas, formarían una unidad génica, lo mismo que las gluconeogénicas, sujetas a inducción o represión según la hormona que, en nuestro caso, no se llegóa ver la regulación hormonal que seria muyinteresante investigar al respecto. Pero Gunn y Taylor (1973) consideran que cada enzima es inducida en forma independiente, como consecuencia de los cambios en los metabolitos, después de la acción aguda de la hormona.

Harper, H. A. (1980) : Manual de Química Fisiológica. Ed. El Manual Moderno S.A. México, 328$332 ; 364$.

Lehninger, A. L. (1978): Bioquímica. Ed. Omega S.A. Barcelona - España, 460 - 462; 475.

Pérez, N.; Turri, C.; Rabayali, E. and Niemeyer, H. (1964): Regulation of rat liver enzymes by natural component of the diet $\mathrm{J}$. Biol. Chem 239: 2420. 